\title{
Geopolítica y asilo. Juego de intereses y principios en la relación argentino- boliviana, 1969-1972
}

\author{
Geopolitics and asylum. Interests and principles in the \\ Argentine-Bolivian relationship, 1969-1972
}

Beatriz Figallo* , María José Henríquez**

\section{RESUMEN}

La Guerra Fría en América Latina ofrece la oportunidad de examinar fenómenos globales bajo el prisma de procesos regionales de gran continuidad histórica. Enfocado en el vínculo argentino-boliviano entre 1969 y 1972, el propósito de este trabajo es analizar cambios y continuidades que se dieron en la práctica de los asilos durante el ciclo de dispares dictaduras militares caracterizadas por un común impulso desarrollista. Se ponen en tensión dos componentes que operan en simultáneo: los controles de la disidencia política, identificada con la expansión de la Revolución Cubana, postulados por la Doctrina de la Seguridad Nacional y la histórica rivalidad de Argentina con Brasil, renovada por el interés estratégico en los recursos naturales de Bolivia. Argumentado por documentación argentina, chilena y española, variedad de prensa internacional y revisión bibliográfica, el artículo concluye que en aquella breve encrucijada conosureña, la razón ideológica se supeditó a la geopolítica.

\section{SUMMARY}

The Cold War in Latin America allows us to examine global phenomena through the prism of regional processes of great histori-
Palabras clave:

Cono Sur, Guerra Fría, anticomunismo, nacionalismo revolucionario.

Argentina. Doctora en Historia Contemporánea. Académica e investigadora, Consejo Nacional de Investigaciones Científicas y Técnicas (CONICET), Unidad Ejecutora en Red (UER) Instituto de Estudios Históricos, Económicos, Sociales e Internacionales (IDEHESI), Nodo Rosario, Pontificia Universidad Católica Argentina. ORCID: https:// orcid.org/0000-0002-4752-5328. E-mail: beatrizfigallo@conicet.gov.ar

** Chilena. Doctora en Historia Contemporánea. Académica e investigadora, Instituto de Estudios Internacionales, Universidad de Chile. ORCID: https://orcid.org/0000-00021474-9982.E-mail: mjhenriq@uchile.cl 
cal continuity. Focusing on the Argentine-Bolivian link between 1969 and 1972, the purpose of this paper is to analyze changes and continuities in the practice of asylums during the cycle of disparate military dictatorships characterized by a common developmentalist impulse. Two components operating are put in tension: the controls of political dissent, identified with the expansion of the Cuban Revolution, postulated by the National Security Doctrine, and the historical rivalry between Argentina and Brazil, renewed by the strategic interest in Bolivia's natural resources. Argued by Argentine, Chilean, and Spanish documentation, a variety of international press, and a bibliographic review, the article concludes that ideological reason was subordinated to geopolitics in that brief crossroads in the Southern Cone region.
Cold War, anticommunism, revolutionary nationalism. 
Aunque a lo largo del siglo XX puede advertirse en Sudamérica un cierto continuum de formas y prácticas exiliares, venían ocurriendo transformaciones en su ejercicio y concesión. Ya desde la conmoción regional que produjo el derrocamiento de Perón, en septiembre de 1955, se experimentaron casos de persecuciones transfronterizas toleradas, consentidas o facilitadas entre los Estados, bien que aisladas (Figallo, 2013: 78). Aquel accionar ejercido sobre la "delincuencia política", que difería de lo que en forma sucesiva se había precisado jurídicamente sobre los asilos y refugios desde fines del siglo XIX, se repetirá en 1964 con el golpe cívico-militar contra el presidente del Brasil João Goulart y luego con el protagonizado por el general de la Fuerza Aérea Boliviana René Barrientos, que el 4 de noviembre del mismo año desplazó al líder del Movimiento Nacional Revolucionario (MNR) Víctor Paz Estenssoro.

Centrada en el vínculo entre la Argentina y Bolivia, esta investigación ${ }^{1}$ pretende articular distintas dimensiones de los asilos y exilios ocurridos en el corazón del Cono Sur durante los años 60 y principios de los 70, en que militares rigieron los gobiernos de ambos países. La sostenida tradición de obtener y conceder protección y amparo presentó, para el caso, dos componentes que perturbaron su aplicación: el uno, propio de los postulados para la región de la Doctrina de la Seguridad Nacional (Leal Buitrago, 2003; Míguez, 2013), que empujaba hacia un mayor control de todo trasiego trasnacional de militantes políticos que mostraban un acercamiento - sino abierta adhesión- al socialismo y a los métodos postulados por la Revolución Cubana, germen del futuro actuar conjunto punitivo de las dictaduras. En segundo lugar, pero casi al mismo tiempo, se desató una fuerza geopolítica capaz de obviar temporalmente la alianza natural de los regímenes castrenses contra la expansión del comunismo y de interferir en la política interregional. El resurgir de la rivalidad histórica entre Argentina y Brasil, estimulado por el proceso de modernización del Estado brasileño que,

Agradecemos a los proyectos CONICET de Unidades Ejecutoras 2018, 229 201801/00003 CO, "El Estado argentino y sus gestores: trayectorias, identidades y disrupciones, 1852/3-2010. De lo disyunto a lo complejo"; IDEHESI, 2020-21, "Dictaduras del desarrollo, ideologías y exilios. El caso de la Bolivia de Torres y la Revolución Argentina, 1970-72" y Universidad de Chile, Programa de Estímulo a la Excelencia Institucional (PEEI) 2018-19, Instituto de Estudios Internacionales, "Allende y la Revolución argentina.1970-1973. Ideología, pragmatismo y desarrollismo". 
a partir de la dictadura del comandante Humberto de Alencar Castelo Branco, hizo retomar la disputa por el predominio en el subcontinente $y$, por ende, la carrera por beneficiarse de la riqueza natural de Bolivia.

Aquellas dos fuerzas operativas, de por sí capaces de atravesar espacios nacionales, se entramaron por algo más de un lustro, irradiando a toda la región. Insertamos esta investigación en las corrientes de renovación historiográfica de los estudios sobre la Guerra Fría (Joseph, 2019), admitiendo la incidencia de procesos de gran continuidad histórica, que se superponen como marco de actuación para determinar comportamientos y decisiones. América Latina porta conflictos preexistentes que en los estudios de la disputa macro entre los Estados Unidos y la Unión Soviética han sido por lo general invisibilizados. Se busca entonces enfocarse en políticas exteriores que asumen mayores dosis de pluralidad, con recorridos que pugnan por alcanzar cierta autonomía en el espacio subregional. Para intentar imbricar las razones geopolíticas con los asilos-exilios que se dieron en la relación argentino-boliviana, nos hemos valido de un rastreo amplio de colecciones de prensa y de noticieros de televisión disponibles en la web, beneficiándonos de la consulta documental en el Archivo Histórico de la Cancillería de la República Argentina (AHCRA), el Archivo Histórico del Ministerio de Relaciones Exteriores de Chile (AHMRECH) y el Archivo del Ministerio de Asuntos Exteriores de España (AMAEE)², así como de aportes bibliográficos.

\section{La convergencia desarrollista}

En Buenos Aires, un golpe militar desplazó al veterano político de la Unión Cívica Radical, Arturo Humberto Illia. La autoproclamada "Revolución Argentina" declaraba su voluntad de acelerar el desarrollo nacional. El empeño, que proponía la integración de las distintas regiones del país con un enfoque productivo, no estaba exento de un sentido geopolítico regional. Dentro de una perspectiva de militarización de la industria pesada, el sector de la metalurgia fue considerado central para el gobierno que presidiría desde ese junio de 1966 y por

Justificamos la importancia de la consulta de estos fondos en razón de los propósitos de política exterior económica que desplegó en América Latina (con particular atracción por el Cono Sur) la España del tardofranquismo, a lo largo de las décadas de 1960 y 1970. Ver Figallo y Henríquez (2009). 
cuatro años el general Juan Carlos Onganía, y luego por sus sucesores los generales Roberto Marcelo Levingston y Alejandro Agustín Lanusse. Por ello, disponer del aprovisionamiento de los recursos naturales de Bolivia, a través de inversiones y de emprendimientos conjuntos, era importante sino indispensable. Los yacimientos ferríferos del $\mathrm{Mu}$ tún, llanos próximos a la ciudad de Puerto Suárez, en el extremo este de Santa Cruz de la Sierra, fronterizos con el Estado brasileño del Mato Grosso, se renovaron como "objeto del deseo" argentino y causa de fricción para las relaciones argentino-brasileño-bolivianas.

A diferencia de Brasil, Argentina no poseía yacimientos de hierro suficientes, de tan buena calidad y accesibilidad. Según Marini y Brody (1967: 9), el régimen militar de Castelo Branco abrigaba "la pretensión de convertir al Brasil en el asiento de la industria pesada de América del Sur, sobre la base de la asociación de capitales nacionales y extranjeros y constituirlos en el proveedor de los bienes intermedios y equipos pesados necesarios a los países vecinos", situación que afectaba sobre todo a la Argentina. Aunque en marzo de 1967, con el respaldo de los sectores nacionalistas de las Fuerzas Armadas, el general Costa e Silva reemplazó a Castelo Branco, generando cambios en el ritmo de la política exterior y reencauzando la económica - proyecto que atrajo incluso a opositores y a exiliados-, en la medida de sus posibilidades, el gobierno argentino se opuso a los planes hegemónicos de Brasil, "complicado esquema subimperialista ideado por el equipo tecnocrátrico-militar brasileño", con medidas que incluyeron el boicot de Onganía a las importaciones del Brasil (Marini y Brody, 1967: 8), y también el acercamiento a Bolivia y a las experiencias militar-populistas de Barrientos y de sus sucesores, Alfredo Ovando y Juan José Torres.

Barrientos, como tantos otros mandatarios bolivianos en el pasado, basculó entre sus dos grandes vecinos. El 1 de enero de 1966 la Junta Militar que gobernaba Bolivia había convocado a elecciones generales, que se verificaron el 3 de julio. Proscripto Paz Estenssoro y Hernán Siles Suazo, el Frente de la Revolución Boliviana que postulaba la candidatura presidencial de Barrientos triunfó, obteniendo incluso mayoría legislativa (Bolivia, 1966). Sin embargo, Bolivia vivía momentos de inquietud. Dispuesto a exportar las luchas de liberación a Sudamérica en el sudeste boliviano, en la zona de Santa Cruz de la Sierra había empezado a operar desde mediados de ese año un foco insurgente, a cuya 
conducción se puso desde noviembre el ya mítico guerrillero cubanoargentino Ernesto "Che" Guevara. Sin auxilio del Partido Comunista boliviano, apenas progresaron sus acciones, aunque contaran con una considerable adhesión entre los mineros, neutralizados a fuerza de la represión del Ejército que ordenara Barrientos. Los voluntarios locales que se sumaron no fueron suficientes para evitar la falta de progreso del movimiento insurgente.

\section{Petróleo y gas}

Habilitada la explotación de los recursos energéticos bolivianos por capitales extranjeros, a través del Código del Petróleo en 1955, Argentina fue la principal interesada tanto en comprar hidrocarburos como en invertir en empresas privadas. Durante la presidencia de Arturo Frondizi (1958-62), aportando las necesarias conexiones de infraestructuras - un poliducto para transportar distintos tipos de petróleo desde el complejo boliviano de Madrejones y un gasoducto desde la provincia de Salta a las de Santa Fe y Buenos Aires (Carrizo y Ramousse, 2010: 54)—, se convinieron importantes adquisiciones de petróleo y gas. En agosto de 1963, con el gobierno de Illia, se concedió una zona franca para Bolivia en el puerto de Barranqueras sobre el río Paraná, se aprobaron fondos para completar obras pendientes del ferrocarril YacuibaSanta Cruz y la construcción del camino Orán-Tarija, para comenzarse en 1965 el Gasoducto Troncal Sistema Norte de Gas del Estado, y así conectar el gasoducto Madrejones con el de Campo Durán, Salta. Para entonces, el gobierno boliviano había otorgado una concesión, por 40 años, de productivas tierras en el norte de Santa Cruz de la Sierra a la empresa estadounidense GulfOil Corporation, luego Bolivian GulfCo., conocida como Bogoc. Para ese año, "las reservas de Bogoc, tanto de petróleo como de gas, eran diez veces más que las de YPFB” (Padilla Rodríguez, 2007: 11).

Ya como mandatario electo por el pueblo, Barrientos puso en marcha un Plan General de Desarrollo, creando el Consejo Nacional de Desarrollo y Estabilización como único organismo con potestad de orientar al gobierno sobre las medidas apropiadas que deberían adoptarse en materia de política económica, financiera y de promoción del desarrollo del país, en reemplazo de los diferentes Consejos Nacionales económicos existentes al momento (Gaceta Oficial de Bolivia, 1966). 
En octubre Barrientos visitó Brasil y, en diciembre, Argentina. Recibido por Onganía y su canciller Nicanor Costa Méndez en Aeroparque, se trasladó a la planta de la Sociedad Mixta Siderurgia Argentina (SOMISA) en San Nicolás, recorriendo el flamante Alto Horno de fundición, siendo recibido por el presidente de la empresa, teniente general Pedro Castiñeiras, y también por el director de Departamento de América del Sur de la Cancillería, Guillermo de la Plaza, personaje que se develaría central para las relaciones argentino-bolivianas. Además de intercambio de condecoraciones, Onganía y Barrientos suscribieron el día 19 una declaración conjunta con el propósito de impulsar la colaboración económica y técnica. Contando con el aporte boliviano, el interés argentino confluía hacía el desarrollo de su mayor centro siderúrgico en la zona Litoral, entre las localidades de Villa Constitución, San Nicolás y Campana, donde estaban instaladas las acerías y laminadoras como Acindar (Industria Argentina de Aceros). Ubicadas a la vera del portentoso río, las empresas públicas y de capitales privados proyectaban recibir la materia prima directamente de las minas bolivianas a través de la ruta fluvial Paraguay-Paraná, aunque el progreso de los transportes y menores fletes no la hicieran ya indispensable como se había calculado en la década de 1940 (Confirmado, 6-4-1967).

Dando inicio de ejecución a lo conversado en Buenos Aires, el 29 de octubre de 1967 tuvo lugar en la ciudad fronteriza de Yacuiba el acto de transferencia a Bolivia, por la Comisión Mixta binacional del ferrocarril, de más de quinientos kilómetros construidos para cubrir la línea hacia Santa Cruz de la Sierra, fruto de los convenios de vinculación firmados al fin de la Guerra del Chaco — en 1965, Brasil habría traspasado a Bolivia el ferrocarril Santa Cruz-Corumbá, también de importancia estratégica, ceremonia en la que volvieron a coincidir Barrientos con Guillermo de la Plaza, enviado en representación de la Cancillería-. Aunque aún se necesitaban algunas tareas complementarias, la difícil obra había demandado más de 25 años de trabajos, y fue inaugurada en 1957 por los presidentes general Pedro Aramburu y el Dr. Hernán Siles Zuazo. Barrientos se mostraba interesado en conseguir un nuevo préstamo para la continuación de la línea ferroviaria hacia el norte, hasta un punto navegable sobre el río Ichilo.

Junto con los planes, arreciaban en Bolivia las críticas por lo que se consideraba la desnacionalización de los recursos naturales (Gan- 
darillas, Tahbub y Rodríguez, 2008: 54). En diciembre de 1967, en el Congreso, el diputado por la minoría opositora Marcelo Quiroga Santa Cruz denunció una política lesiva para los recursos naturales bolivianos (Rodas Morales, 2010: 417). Las operaciones continuaron y, en julio de 1968, el Ministerio de Minas y Petróleo boliviano acordó con la empresa argentina Yacimientros Petrolíferos Fiscales (YPF) la compra de gas, de la que se beneficiaba en primer término la Gulf, que detentaba la explotación de los terrenos más productivos, aunque la transacción fuera gestionada en Buenos Aires por la embajada y una delegación de Yacimientos Petrolíferos Fiscales Bolivianos (YPFB) (Rodas Morales, 2010: 452). Si Bogoc firmó el contrato del gas por veinte años, otra empresa vinculada a ella obtuvo otra concesión para la construcción del gasoducto de Bolivia a Argentina (Colpa-Yacuiba) (Padilla Rodríguez, 2007: 11).

Argentina se dispuso a ofrecer más incentivos para que el mecanismo de producción, exportación y desarrollo funcionara. El 11 de diciembre ambos países firmaron notas reversales para hacer posible la entrega de una nueva zona franca en el puerto de Rosario - en las inmediaciones del polo siderúrgico-, lo cual significaba "un gesto político de suma importancia en las relaciones entre ambos países y para Bolivia una solución a los problemas que su situación geográfica le plantea en relación con el comercio exterior" (AMAEE, Buenos Aires, 3-III-1969; La Paz, 14-III-1969). Se trataba de una superficie de seis hectáreas, con facilidades aduaneras para liberar de gravámenes a las mercancías bolivianas, pudiendo Bolivia instalar depósitos y unidades industriales para elaboración de materias primas propias. Era renovar la antigua expectativa por alcanzar el Atlántico para vender su producción, mientras el gasoducto era el medio para vender gas natural en el mercado argentino, a precios favorables para el país.

Pero Barrientos no firmaría el convenio, pues fallecería en un accidente de helicóptero en la zona de Cochabamba el 27 de abril de $1969^{3}$. En un acto que tuvo lugar en La Paz el 4 de junio, lo suscribió su

En marzo de 1971, siendo el general Ovando embajador de su país en España, a raíz
de la denuncia hecha por un ciudadano alemán, culpándolo de haber ordenado disparar
contra la nave, se llevaron adelante algunas diligencias sobre los restos del aparato y de
los cuerpos, sin conocerse conclusiones definitivas. El embajador norteamericano Ernst
V. Siracusa sería de la opinión que Barrientos "was killed in a helicopter crash" (1998: 49). 
vicepresidente, a cargo del Poder Ejecutivo, Luis Adolfo Siles Salinas, siendo rubricado por el subsecretario de Relaciones Exteriores de Argentina Jorge A. Mazzinghi y por el ministro de Exteriores de Bolivia, Gustavo Medeiros Querejazu.

Un acontecimiento imprevisto pareció desbaratar los planes trazados. Desplazado Siles Salinas, los militares impusieron en el poder al general Alfredo Ovando que asumió el 26 de septiembre, quién a los pocos días derogó el Código del Petróleo. Frente al denunciado "entreguismo" de Barrientos a los intereses de los Estados Unidos, el gobierno de Ovando se pronunciaba a favor de la defensa de los recursos naturales y los medios de producción bolivianos. Para que el sistema comenzara a funcionar fue necesaria la nacionalización de la boliviana Gulf Oil Co., poderosa empresa que por segunda vez era expropiada - antes lo había sido en la década de 1930-, traspasándose sus instalaciones a YPFB. Se asumió el contrato de venta de gas suscrito con Argentina y se destinó a la empresa estatal Gas y Petroquímica el financiamiento para la construcción del gasoducto. Se creó también la primera fundidora de estaño, recuperándose los yacimientos de la Mina Matilde - también concesionados- cerca del lago Titicaca, así como se impulsó la metalurgia en Oruro.

Era visible que detrás del nuevo presidente existía un grupo, un "frente organizado", que incluía figuras del pensamiento joven boliviano, de centro e izquierda, como Marcelo Quiroga Santa Cruz — nombrado ministro de Minas y Petróleo-, Mariano Baptista Gumucio o José Ortiz Mercado, asociándose los nombres de otros militares de mediano rango.

\section{Un embajador amigo y necesario}

La Argentina de Onganía designó a Guillermo de la Plaza como representante ante el nuevo gobierno de $\mathrm{Ovando}^{4}$. Resultaba la figura con-

\footnotetext{
$4 \quad$ Nacido en Buenos Aires en 1918, hijo de familia salteña, Guillermo de la Plaza ingresó en el Servicio Exterior de la Nación en marzo de 1958, siendo nombrado embajador extraordinario y plenipotenciario en 1967. De adscripción nacionalista, "enrolado en la lucha estudiantil anticomunista", desde 1947 manifestó su oposición al gobierno de Juan Perón, participando del levantamiento de 1951, por el que fue preso y luego se exilió en Uruguay. Durante el régimen del general Aramburu, en 1957, fue interventor de la provincia de Formosa, limítrofe con Paraguay.
} 
veniente para reconducir la situación ante el cambio de condiciones que presagiaba dificultades capaces de afectar la provisión de hidrocarburos. La Gulf embargó las exportaciones de petróleo boliviano y se movilizó para que se suspendieran los créditos internacionales y el suministro de insumos para la construcción del gasoducto, hasta que Bogoc quedara satisfecha con los términos de la nacionalización (Padilla Rodríguez, 2007: 11).

Doctor en Ciencia Política por la Universidad del Salvador, de tradición jesuita, la tesis doctoral del flamante embajador había versado sobre el "Rol protagónico de la Argentina en América". Su ideario lo había difundido en círculos diplomáticos y políticos afines, así como lo hizo público ante militares de la Revolución Argentina. En oportunidad del IV Curso Interfuerzas, realizado en el Centro de Altos Estudios del Ejército, en octubre de 1968, con un auditorio compuesto por oficiales superiores de las tres ramas de las Fuerzas Armadas, reivindicó la línea histórica que constituía la identidad nacional y la vocación americanista de la Argentina. Manifestó que era urgente y decisivo solucionar los problemas internos, "pues no es posible impulsar una gran política internacional sin lograr los grandes objetivos nacionales (...) que abarque todos los planos del desarrollo nacional", siendo indispensable "la conformación firme y exacta del tipo argentino que engendra una mentalidad homogénea y no discrepante". Ello era necesario para dar una "respuesta válida" al reto comunista, cuestión en la que insistirá en su exposición:

“...nuestra revolución debe proseguir para que no haya más Cubas marxistas ni Conferencias comunistas en suelo de Hispanoamérica (...) La intromisión comunista y la agresión subversiva en la política del Hemisferio ponen a prueba la solidaridad americana y los objetivos nacionales. Ha sido ya harto demostrado que el comunismo no cree en la paz ni en la recuperación económica, y que solo confía - para triunfar- en el caos, en la miseria y en la ignorancia".

[El influyente funcionario expresaba su confianza en el] "desarrollo como base efectiva para la lucha contra la acción subversiva" [y en las] "enormes reservas energéticas, en forma de carbón, petróleo y saltos de agua" [para] "llegar a dar forma definida a una gran industria siderúrgica si conjugamos nuestros esfuerzos y nos proponemos una meta común con los países latinoamericanos" (Círculo Diplomático Argentino, 1969: 54). 
"Sin desarrollo la seguridad es utopía", reflejaba una postura congruente con lo planteado por un sector importante de los militares como los generales Esteban Iavicoli, compañero y amigo de Onganía, Osiris Villegas y Juan Enrique Guglialmelli.

Al frente de la representación en La Paz desde el 10 de enero de 1970, De la Plaza se dedicó con dinamismo a cuestiones culturales -donaciones de libros, bancos, material didáctico para escuelas, organización de una filial del Instituto Nacional Sanmartiniano, reestructuración del Instituto Cultural Boliviano-Argentino, realización de exposiciones pictóricas, presentaciones de filmes y conjuntos de música y danza - y a la cooperación - entrega de medicamentos y vacunas-. Todo esa actividad quedaba en un plano social, que no interfería con los propósitos principales de su misión, la que se extendió por 16 meses: asegurar abastecimientos para Argentina y crear una serie de intereses compartidos.

Se reanudaron las compras de partidas de hierro del Mutún y, en marzo, De la Plaza firmó con el ministro de Relaciones Exteriores, el general César Ruiz Velarde, el "Acuerdo de Cooperación de los Usos Pacíficos de Energía Nuclear", que sería ratificado en Buenos Aires en enero de 1971. Se inauguraron también los servicios internacionales de la Empresa Nacional de Telecomunicaciones de Argentina (ENTel). Lo principal se logró el 31 de diciembre cuando se firmaron en La Paz las notas reversales en las que se planteaba la intención de construir una ferrovía que, pasando por el Mutún, permitiera exportar el hierro desde el mismo yacimiento. Se proyectaba vincular el apartado y despoblado Puerto Busch — una especie de El Dorado para países y gobiernos - con la red oriental de los ferrocarriles bolivianos sobre la línea Santa Cruz, como vía de comunicación atlántica, en el contexto de un plan de desarrollo regional, ya que estaba emplazado junto al río Paraguay y era una promesa de salida independiente del contralor de Brasil (Argentina. Ley 21.202, 13-11-1975). El acuerdo firmado prometía estudiar la continuación de la construcción del ferrocarril Santa Cruz-Mamoré - se había inaugurado un tramo de 45 kilómetros con la presencia del presidente de Ferrocarriles Argentinos y el administrador del Ferrocarril Belgrano-, proponiendo la prolongación y la unión de distintas líneas férreas bolivianas (de la Plaza, 1985: 125-6). 
La embajada trató con el gobierno de Ovando la cuestión de la construcción del gasoducto Yacuiba-Santa Cruz, apelando al Banco Mundial para conseguir un crédito y su aval. En la mesa de negociaciones se sumaron representantes de España, que venía colaborando con La Paz a través de asesorías y envío de especialistas, para aconsejar en la construcción y financiación del gasoducto y la comercialización en el exterior de un crudo que se almacenaba luego de la estatización, no consiguiendo Bolivia mercados a quienes vendérselo. La delegación española era parte de grupos oficiales y de empresarios privados extranjeros que pululaban por el altiplano en busca de beneficiarse con contratos e inversiones. Después de un crédito concedido en 1966 por el régimen del general Francisco Franco a Barrientos, España envió una delegación y, en julio de 1971, el mismo ministro de Relaciones Exteriores Gregorio López Bravo llegó a La Paz para tantear la participación en los negocios que se abrían. Apenas se lograrían firmar algunos acuerdos sobre cooperación técnica y social (AMAEE, Bolivia, 7.3., 30-VI-1971).

En tanto, la gestión diplomática de Guillermo de la Plaza había concluido a fines de mayo en un clima de cordialidad con el régimen boliviano, "las muestras de que su labor ha sido muy positiva lo dan las despedidas y agasajos que todos los días recibe él y su esposa (...) mañana domingo la esposa del presidente Torres lo despedirá con un agasajo en los salones del Palacio Quemado" (Clarín, 30-V-1971). Ni siquiera los asilos diplomáticos concedidos a enemigos del gobierno de Torres habían afectado la sintonía. La Cancillería lo reclamaba desde Buenos Aires, en lo que se consideraba una promoción, para ocupar el cargo de director general de Política.

A diferencia de la desilusión española, las relaciones entre Bolivia y Argentina continuaron de forma armónica: entre el 7 y 13 de julio de 1971 el canciller Huáscar Taborga Torrijo firmó en Buenos Aires una serie de acuerdos de cooperación cultural, científica y técnica, "en acción dirigida a mantener la vinculación espiritual e histórica de ambos pueblos" ${ }^{\prime 5}$. Si la inestabilidad institucional no contribuyó a rápidas so-

5 Por esos días, la política exterior argentina daba otro paso audaz, al entrevistarse el general Lanusse con el presidente chileno Salvador Allende en la ciudad de Salta, el 24 de julio de 1971. 
luciones y acciones, retrasando gestiones ante el Banco Mundial y el Banco Interamericano de Desarrollo (BID), los préstamos necesarios para la instalación del gasoducto Santa Cruz-Yacuíba se concretaron entonces, pudiendo avanzarse con la retrasada obra. Aunque, tras la nacionalización, la Gulf paralizó la exportación del crudo boliviano por el puerto de Arica, la venta mejoró cuando YPFB pasó a venderle a las empresas estatales peruanas y chilenas a un precio alto (AMAEE, 30-VI-1971).

Al partir, Guillermo de la Plaza había dejado todo anudado para que en 1972 se pudiera cosechar buenos frutos de su gestión: al impulso del aumento internacional de los precios del petróleo, Bolivia había conseguido indemnizar a la Gulf (Padilla Rodríguez, 2007: 12) y se había concluido con la construcción del gasoducto a Argentina, que permitió la exportación de gas natural a partir de mayo proveniente de los campos que explotaba ahora YPFB, ampliándose luego el acuerdo a veinte años.

\section{El factor ideológico}

El retorno del ciclo militar al poder en Bolivia no había logrado estabilizarse. Los afanes de desarrollo, basados en el aprovechamiento de sus recursos naturales, coexistieron con una gran efervescencia política de su sociedad y, además, con la insurgencia, ámbito en el que los altos mandos de las Fuerzas Armadas bolivianas (FAB) se considerarían vencedoras y protagonistas de una sonada derrota de los terroristas, ubicándolos como una amenaza de intervención extranjera contra la soberanía nacional.

El 30 de junio de 1967, el general Ovando, que entonces era el comandante de las Fuerzas Armadas, declaraba en una entrevista en La Paz que el movimiento insurgente encabezado por Guevara era de "carácter internacional (...) se proponen conseguir un cambio político en Iberoamérica", conociéndose la información por la declaración de testigos y también del periodista e intelectual francés Regis Debray, detenido bajo la acusación de estar colaborando con las guerrillas. El presidente Barrientos, a su vez, declaraba a la prensa paceña "que se trataba de una grave intromisión internacional preparada por el eje La Habana-Pekín". Mientras la Argentina y Perú habían reforzado el control de las fronteras, los militares brasileños señalaban la "peligrosidad 
de la guerrilla boliviana por tener extranjeros, sobre todo cubanos, aliados de la Unión Soviética"6. El 30 de septiembre Barrientos había llegado a Vallegrande para hacer acto de presencia anticipando una derrota de los guerrilleros, y dando la orden de ejecutar al "Che"

Dos años después, con Ovando presidente conformando un frente revolucionario de tipo nacionalista, sus medidas referidas a la protección de los recursos naturales no alcanzaban para frenar un tiempo de exacerbación de demandas sectoriales - militares, universitarios, fuerzas sindicales y obreras, grupos cristianos-. A pesar de la abolición de la ley de Seguridad del Estado con la que gobernó su predecesor, de campañas alfabetizadoras, mayores grados de libertad ciudadana y de prensa, se asumió un rol represivo contra movilizaciones de estudiantes y obreros.

No obstante esas contradicciones, el general Ovando también gozó de popularidad, casi como Barrientos. Considerado "cabeza visible de la actividad antiguerrillera, campeón de la lucha contra la subversión foránea" (Panorama, 30-IX-1969), los noticieros de la época mostraban cómo se lo recibía en actos públicos y giras con gritos de “¡abajo el imperialismo yankee!". Les insistía a sus camaradas que, aunque había quién los identificaba de comunistas o castristas, "sepan que no lo son, que son nacionalistas, que están en el Tercer Mundo que no pertenece al mundo del capitalismo, ni pertenece al mundo del socialismo"8. Aunque las agencias de noticias internacionales transmitían la impresión de que se trataba de un gobierno "izquierdista-nacionalista" ( $L a$ Vanguardia, 29-VIII-1970), el ovandismo reivindicaba ser un "nacionalismo con avance revolucionario gradual”, con una proyección hacia

\footnotetext{
6 Documentos del Estado Mayor de las Fuerzas Armadas de Brasil, liberados en agosto de 2013 y reproducidos por las agencias informativas ANSA y DPA: https://www.telam. com.ar/notas/201308/28399-la-dictadura-argentina-aporto-napalm-a-bolivia-paracombatir-al-che.php, revisado el 18-III-2021.

$7 \quad$ El diario El País, Madrid, en el artículo "Barrientos y Ovando, víctimas prominentes", 11-VI-1976, señaló que el ejército boliviano no podía hacer otra cosa que enfrentarla cuando apareció la guerrilla guevarista y lo hizo con eficacia, señalando que no fueron los Boinas Verdes norteamericanos del comandante Ralph Shelton, que llegaron como instructores a Santa Cruz, los autores de la campaña, sino los jóvenes oficiales y humildes soldados quechuas y aymaras, los que derrotaron a los insurgentes, en una prueba que sirvió para rehabilitar a las Fuerzas Armadas bolivianas en su capacidad operativa. 8 Ver el documental Algo quema (2018), con guion y dirección del nieto del general, Mauricio Alfredo Ovando.
} 
un Estado moderno, por encima de ideologías. Pero no faltaban mensajes ambiguos: el encargado de negocios en París, Alberto Salamanca, había expresado, "en el equipo del presidente Ovando, que intenta liberar a nuestro país de la garra imperialista, nos sentimos solidarios con algunas medidas del gobierno cubano" (Periscopio, 24-II-1970).

Poco tardaron sectores de derecha del Ejército para presionar a Ovando, plegándose a las advertencias que surgían de grupos conservadores en el sentido que la ultraizquierda infiltraba su gabinete, a la par que grupos económicos tradicionales expresaban preocupación por las nacionalizaciones e intervención del Estado en distintas actividades productivas. En febrero, oficiales del Ejército interrogaron a ministros civiles sobre planes y conductas. El 14 de marzo se produjeron serios incidentes, con multitudinarias manifestaciones de repudio a la llegada del enviado norteamericano Charles Meyer, subsecretario de Estado. El 18 de mayo renunció el ministro Quiroga Santa Cruz (Rodas Morales, 2008: 298) $)^{9}$ y se publicitó el desbaratamiento de una conspiración que se atribuyó al MNR de Paz Estenssoro, siendo arrestados numerosos políticos. Aparecieron en junio los cadáveres, con signos de tortura, de la universitaria y dirigente de la Democracia Cristiana Genny Koeller y del periodista chileno Elmo Catalán, militante del ELN, en Cochabamba (Salazar Calvo, 2020). Ello hizo estallar una violenta reacción estudiantil, se apedrearon centros militares, sucediéndose mitines, a la par que el Ejército reprimió con armas de fuego los disturbios. Ovando procedió entonces a reorganizar su gabinete, eliminando a algunos connotados "izquierdistas" (La Vanguardia, 29-VIII-70).

En ese contexto de gran polarización política, se produjo un rebrote guerrillero (Rodríguez Ostria, 2005; 2018-2019). Dentro y fuera del monte, algunos adherentes se incorporaron a un grupo dirigido por supervivientes de la campaña del "Che" — se habla de 1.000 simpatizantes y menos de 100 combatientes-. La lucha armada se asumió como alternativa válida, aunque objetable por quienes no vieron la oportuni-

\footnotetext{
$9 \quad$ Después del golpe de Banzer, de agosto de 1971, se exilió en el Chile de Allende y luego en la Argentina, donde colaboró en el diario Noticias y dictó clases en la Universidad de Buenos Aires. Perseguido por la Triple A, se radicó en México, desempeñándose como profesor de Economía Política en la UNAM. Regresó a Bolivia en 1977, volvió a la política, siendo asesinado durante la dictadura de Luis García Meza en julio de 1980. Disponible en https://www.tiempoar.com.ar/nota/un-lamento-boliviano, revisado: 2-IV-2021.
} 
dad de enfrentarse a un gobierno como el de Ovando, que tenía arraigo popular. Para mediados de 1970, los insurgentes ya incursionaban por la zona selvática y montañosa de Teoponte, al norte de La Paz. En Chile, dada su condición fronteriza, la cercanía del reinicio de la actividad guerrillera impactó en momentos que tenía lugar la campaña electoral para elegir presidente, en la que, impensadamente, el 4 de septiembre triunfó Salvador Allende, un marxista declarado, sucediéndose días de vertiginosa tensión hasta su proclamación por el pleno del Congreso y el inicio de su mandato el 3 de noviembre. Desde Santiago, la revista Punto Final decía que la guerra revolucionaria había dejado de ser un asunto lejano para los chilenos, además que comprometían en su acción al resto de combatientes de países vecinos, como Argentina, Brasil, Paraguay y Perú (Marchesi, 2018-2019: 130).

Con Bolivia en estado de sitio, en julio se iniciaron las operaciones militares y las bajas. Apoyados por sacerdotes y religiosas, los familiares demandaban la entrega de los cadáveres de los guerrilleros abatidos, con huelgas de hambre y detenciones. La espiral de violencia crecía: mientras se producían sangrientos enfrentamientos callejeros entre los estudiantes y las fuerzas del orden, en septiembre se detuvo a varios religiosos, algunos jesuitas y un pastor protestante, y se los expulsó a la Argentina (Suárez, 2003: 146). La embajada española cursó una nota de protesta por el trato dispensado a los sacerdotes de origen español, sin darles oportunidad de defenderse de los cargos que les imputó el Ministerio del Interior (La Vanguardia, 3-X-1970), aunque confidencialmente reconocía que éstos se habían politizado, "formando la avanzadilla de los partidos revolucionarios", pues "los sacerdotes extranjeros que aquí viven, observan la miseria del pueblo y se entregan a sus reivindicaciones, casi en su totalidad" (AMAEE, Bolivia, 7.4., 30-VI-1971).

\section{Las pseudotransiciones militares: de Levingston a Lanusse, de Ovando a Torres}

La pugna por el poder en los gobiernos de Argentina y Bolivia se fue resolviendo casi en modo paralelo, tanto en 1970 como en 1971. Tras la rebelión obrero-estudiantil de Córdoba, en mayo de 1969, y un año después el secuestro - y posterior asesinato- del ex presidente Aramburu, la Junta de comandantes de la Revolución Argentina desplazó a 
Onganía, nombrando en su reemplazo a Levingston en junio de 1970. Meses más tarde, hacía eclosión la abierta división en las FAB entre los revolucionarios de tendencia nacionalista y los grupos de derecha, quienes le exigieron a Ovando "devolver" el cargo a una "Junta Militar". La misiva fue secundada por el comandante del Ejército Rogelio Miranda, quien el 3 de octubre se "levantó en armas". Al día siguiente, varios jefes militares se parapetaron en el Gran Cuartel de Miraflores, secundando el motín. Miranda contaba también con el apoyo político del MNR y del PDC. Tropas dependientes del Estado Mayor General y el Colegio Militar cercaron La Paz. Ovando dimitió, a pesar de que la joven oficialidad que lo rodeaba, algunos excombatientes de las fuerzas rangers contra la guerrilla del "Che", anunciaban que lo defenderían de los sectores militares que lo querían traicionar. Se asiló en la representación argentina, aunque regresó pronto a su casa, para ser luego enviado como embajador a España. Removido a los pocos meses de su cargo diplomático, permaneció exiliado en Madrid hasta 1978.

Pero el golpe que desplazó a Ovando no consiguió consolidarse. El 6 de octubre se entregó el poder a un triunvirato conformado por los comandantes de las tres fuerzas, de tendencia conservadora. La junta declaró que gobernaría hasta 1971, cuando se celebrarían elecciones. Pero los seguidores de Ovando respaldaron a otro candidato para alcanzar la presidencia, el general Juan José Torres, contando también con el apoyo de la huelga general de la Central Obrera Boliviana (COB), así como de un "activo comando de partidos populares" que terminaron por definir el conflicto (Rodas Morales, 2008: 321).

Torres había estudiado artillería en la Argentina en 1946, presidida entonces por Juan Domingo Perón (Siete Días, №180, 9 al 25-X-1970). Opuesto al golpe para impedir la victoria electoral del MNR, el joven oficial fue dado de baja del Ejército y volvió exiliado a la Argentina peronista, hasta que pudo regresar a Bolivia al triunfar la revolución de 1952, para reincorporarse a la vida militar (Guerra Vilaboy, 2021). El embajador franquista Víctor Sánchez-Mesas y Juste escribía:

“Muy ambicioso, no se le conocía fuera muy de izquierdas, hasta que durante el régimen de Ovando (1970) éste suprimió el cargo de Comandante de las Fuerzas Armadas, segundo puesto en el Ejército después del Presidente. Para contentarle Ovando le mandó a Lusaka [Zambia] a la Reunión de Países no alineados. Su contrin- 
cante del 7 de Octubre, el General Rogelio Miranda, protegido del General Lanusse, pudo entonces aprovechar la ocasión para dar el golpe, pero no le consideró bastante enemigo. Cuatro meses antes del enfrentamiento comieron ambos en esta Embajada situados a la derecha e izquierda de mi esposa. La increíble estupidez del General Miranda dejando al General Torres subir al Aeropuerto de El Alto y su inacción frente a las proclamas de la radio, dieron al último el triunfo en bandeja" (AMAEE, Bolivia, 7.2, La Paz, 30-VI-1971).

La mayoría de los militares descontentos con el desenlace recurrieron a los asilos diplomáticos. Miranda pidió asilo en la embajada del Paraguay y, aunque se retiró cuando hubo un conato de reacción, los fuertes apoyos de otros sectores castrenses y sobre todo de obreros, campesinos y estudiantes a Torres, lo llevaron a volver a asilarse, esta vez en la embajada argentina. El 18 se informaba que el ex comandante en jefe del Ejército salió en avión en dirección a Buenos Aires. Algunos oficiales del Ejército, entre ellos el exministro de Ovando coronel Juan Ayoroa, recibieron asilo en la embajada uruguaya.

Mientras tenían lugar estos incidentes, Torres buscó consolidar su gobierno en la región. Hizo declaraciones al enviado especial del diario Express de Lima, que reprodujo EFE:

"Procederemos a la integración vertical de la industria minera, con participación del Estado, a fin de llegar al mercado con productos acabados (...) En materia de política minera diversificaremos las exportaciones. En la actualidad sólo exportamos estaño y tendremos que vender otros minerales para evitar la extrema vulnerabilidad de nuestro comercio exterior dependiente en gran porcentaje de ese producto".

Y enfatizó: “Mi Gobierno no es, ni será, de extrema izquierda. Será un Gobierno netamente nacionalista". Profundizó en sus definiciones en la entrevista que concedió a Siete Días el 13 de octubre:

"El nacionalismo revolucionario es el movimiento político más importante del Siglo XX. En Bolivia está presente en su fuerza armada y en todo el pueblo, como se ha visto en la última crisis. Expresión de la alianza de la clase media, de los obreros y de los campesinos, el nacionalismo revolucionario busca romper el statu-quo y la dependencia, a fin de lograr una sociedad donde exista una mayor 
movilidad social y mejores oportunidades y donde, además, se consolide el Estado nacional".

Aduciendo que existía "una incompatibilidad tácita entre el nacionalismo revolucionario y el comunismo", afirmó "que la campaña antiguerrillera [de 1967] ayudó a un robustecimiento de la conciencia nacionalista, pero ésta no se redujo al sector militar únicamente, sino que alcanzó a todos los sectores de la nacionalidad que, ante el fracaso de ese planteamiento armado, reafirmaron su fe en el nacionalismo revolucionario" ${ }^{10}$. Se mostró firme en cuanto a la guerrilla de Teoponte: "mi gobierno rechaza toda forma de subversión", aunque dudoso de la posibilidad de formar un bloque ideológico con Perú y Chile, "entiendo que el Doctor Salvador Allende ha planteado otras soluciones para resolver la problemática chilena".

Su poder no era, en realidad, tan sólido. Distintas fuentes señalaban que no había acuerdo entre los militares para enfrentar el resurgir guerrillero, siendo contestado Torres por la plana mayor de las Fuerzas Armadas, "o sea, con muchos de sus enemigos jurados" (Gutiérrez, 1970: 5). Junto con algunos sectores civiles inspirados por Paz Estenssoro, eran señalados como los artífices de conspiraciones que programaban "un golpe contra Torres y su línea populista" (Confirmado, 28-X1970). El intento de sus seguidores de crear una fuerza política propia llamada "Alianza Popular Revolucionaria", iniciada en Santa Cruz, no prosperaría. Según consignaba un corresponsal de prensa español, sus órdenes se desconocían: no se habilitaba el ingreso a la zona de una Comisión de la Cruz Roja para rescatar guerrilleros hambreados y supervivientes; se dilataba la entrega de cadáveres a los familiares; se continuaba fusilando a combatientes que se rendían en acatamiento a las exhortaciones presidenciales. En tanto, Torres dio curso en diciembre a la liberación de los condenados por un tribunal militar a 30 años de prisión por colaborar con el "Che", Debray y su compañero de prisión en Camiri, el argentino Ciro Bustos —una peligrosa iniciativa

10 La revista argentina Siete Días, No 180, señalaba: "En rigor, Torres tuvo una escasa participación en la lucha antiguerrillera de 1967. Jamás viajó a Estados Unidos y no es cierto que haya asistido a los cursos que se dictan en la zona norteamericana de Panamá. Simplemente concurrió a ese país a una reunión de los comandantes en jefe de los ejércitos americanos. Sus últimos viajes fueron a Zambia, donde presenció como observador un plenario de países no alineados, y a Madrid, para visitar a su hija mayor Emma (18) que estudia administración de empresas". 
de un "incipiente y no consolidado régimen" - . La liberación se debió llevar adelante en medio de grandes reservas, para evitar la reacción de los militares de derecha (Gutiérrez, 1970: 5). Aunque en pocos meses los guerrilleros fueron otra vez derrotados, los militares complicaban la pacificación que procuraba Torres, quién advertía a los jefes que su gobierno se atribuía el derecho de armar a los trabajadores en caso de un levantamiento de la derecha, promesa hecha en las visitas a las minas.

\section{El factor geopolitico}

Después del gobierno de Costa e Silva, se fue haciendo cada vez más notorio el avance económico del régimen militar brasileño, en desmedro de la paridad de fuerzas con Argentina en el Cono Sur. Extinto su mandato a fines de agosto de 1969, y con él su diplomacia de prosperidad, la gestión del general Emílio Garrastazu Médici y su canciller Mário Gibson Barbosa encaró un reajuste de su política exterior, la "Diplomacia do Interesse Nacional", pragmática pero ambiciosa, con una estrategia bilateral cercana a los Estados Unidos y dispuesta a hacer ingresar a Brasil al Primer Mundo, abandonando veleidades tercermundistas (Vizentini, 1998-1999). Médici y Gibson Barbosa mostrarían el rechazo de muchas de las medidas emprendidas por Bolivia, nación que quedaba envuelta en el trazado de lo que distintos autores han señalado como los "círculos concéntricos", áreas estratégicas que aseguraran la estabilidad brasileña continental, incluyendo ello la proyección sobre América del Sur que, por razones políticas y de seguridad, estaba en primera línea de actuación (Araujo y Teixeira, 2015: 3). Los intereses brasileños en Bolivia incluían también el objetivo de obtener gas y hierro, en la convicción de que sus yacimientos eran una reserva de la que convenía siempre estar en posibilidades de disponer, y de paso beneficiar empresas privadas brasileñas y estadounidenses.

Brasil, como en la década de 1930, se atravesaba en el camino de la Argentina para obtener los recursos minerales bolivianos, debiendo mantenerse como exportadora de carnes y granos, en tanto Brasil podría ascender a potencia industrial (Araujo y Teixeira, 2015: 14); para ello era necesario, además, incidir en la región para evitar alianzas que incluyeran a Buenos Aires o alineamientos con movimientos de 
izquierda, fueran de militares nacionalistas o del gobierno de Allende en Chile.

Para enfrentar con más desarrollo propio la creciente embestida brasileña, la Argentina profundizó su opción por Bolivia, incluso con Torres al frente del gobierno desde octubre del 70, convergencia que también interesaba en La Paz para evitar su aislamiento en la región, sobre todo del frente que constituían Brasil y el Paraguay de Stroessner. Ante una pregunta concreta sobre los virajes de Chile y Bolivia (Allende y Torres), el presidente Levingston respondía que era analizables "como experiencia histórica contemporánea, incorporándolos a los factores que debemos tener en cuenta para la solución de nuestros problemas durante el proceso revolucionario" (Clarín, 11-X-1970). Nuevo presidente argentino desde marzo de 1971, el general Lanusse explicaría que fue necesario "generar la imagen de una política independiente, sin prejuicios, sin barreras ideológicas, y capaz de ser apoyada por el grueso de la población", respetando la "no intervención en los asuntos internos de otro" (Lanusse, 1977: 240). Eso aunque implicara acercarse a los gobiernos militares de tipo nacionalista-izquierdista (Perú y Bolivia), o al gobierno socialista de Chile, que estaban protagonizando las experiencias más activas de la región. Se había avanzado en esa dirección con Levingston y su canciller Luis María de Pablo Pardo, quien permaneció en el cargo, y se profundizaría con Lanusse. La justificación: era necesario superar posiciones de dogmático aislamiento por ser causa de perjuicio para los intereses argentinos en América del Sur.

Entre los militares argentinos convivían diferentes posturas porque, amén de la cuestión geopolítica, de la necesidad de neutralizar el movimiento que, desde su exilio, agitaba el expresidente proscripto Perón, pesaba con pareja fuerza el anticomunismo y el temor a la expansión de la guerrilla. En noviembre, en la provincia argentina de Formosa, se realizaron maniobras conjuntas de los ejércitos argentino y brasileño, en una zona cuya cercanía con Bolivia daba a dichos ejercicios un matiz intimidatorio. Refiriéndose a esas operaciones, el general Alcides López Aufranc, comandante del III Cuerpo del Ejército, señaló a la prensa que Argentina y Brasil estaban creando un "Frente Atlántico", en oposición a un presunto "Frente del Pacífico", que integrarían los inquietantes gobiernos de Chile, Perú y Bolivia. López Aufranc añadió que se trataba de prever la necesidad impostergable de una "función 
policial" en el Cono Sur contra los posibles extremismos. Recordó, para los familiarizados con la historia latinoamericana, la Guerra de la Triple Alianza que los ejércitos de Argentina, Brasil y Uruguay libraron contra otro gobierno considerado díscolo e inquietante: el Paraguay de Francisco Solano López (Gutiérrez, 1970: 5).

En tanto, la experiencia de Torres entusiasmaba y alarmaba. Los Estados Unidos se sentían particularmente afectados por las nacionalizaciones, el obligado retiro del Centro de Transmisiones Estratégicas, el cierre de instituciones culturales norteamericanas y la expulsión de los voluntarios del Cuerpo de Paz, acusados de actos de espionaje. Se señalaba en la prensa local que los dirigentes de la $\mathrm{COB}$ habían exigido a Torres la salida de todos los instrumentos del "imperialismo yankee". Por otro lado, durante su gestión se inauguró la fundición de estaño de Vinto, obra de gobiernos anteriores instalada por técnicos de Alemania Federal, que permitía vender el metal en diversos mercados del mundo, transacciones sometidas, no obstante, a posibles bajas de su cotización en el mercado de Londres, o debido a la venta por Estados Unidos de su stock almacenado. Faltaban también compradores para el zinc que se extraía de la Mina Matilde, determinando al gobierno a no indemnizar a la empresa arrendadora que había dejado "unas instalaciones modernas y productivas" (AMAEE, Bolivia, 7.2., La Paz, 30-VI-1971). El anuncio que realizó Torres al tomar el poder, de cambiar la estructura económica boliviana, promocionando las industrias básicas en un periodo de 20 años, parecía un exceso de optimismo.

Las percepciones externas sobre el gobierno iban de un expresivo entusiasmo social y ciudadano en la región, a los negativos informes de los diplomáticos extranjeros acreditados en La Paz. El embajador norteamericano Ernest Siracusa era de la opinión que Torres fue perdiendo apoyos militares, mientras los sectores que lo sostenían - sindicatos, universitarios, prensa- tenían diferentes objetivos, no siempre compatibles. En testimonios muy posteriores señaló que habían alarmado la instalación de asambleas y de tribunales populares a semejanza de Cuba, así como la creciente dotación de diplomáticos soviéticos: "many thought Bolivia under Torres was on the verge of becoming another Cuba, but this one in the heart of South America" (Siracusa, 1998: 63). Para el embajador español, no había seguridad que no 
fuera a una radicalización de sus posiciones, "aunque no tenía un líder que arrastrase a las masas como ha sido Fidel Castro en Cuba". No obstante, en la entrevista con López Bravo - ocurrida poco más de un mes antes de ser derrocado-, Torres insistió con la posición que su "régimen no es comunista ni pretende serlo, pero después de gobiernos cortos y corrompidos eran inevitables ciertas medidas, como la Asamblea Popular" (AMAEE, de López Bravo a Carrero Blanco. 3-VII-1971).

\section{Los asilos}

En un contexto regional de gran circulación de la disidencia y oposición política, la Argentina venía recibiendo expulsados por el gobierno del general Ovando. Había llegado un grupo de políticos entre los que estaba el excanciller Víctor Andrade; en julio de 1970 arribó otro contingente que incluía al exvicepresidente Nuflo Chávez Ortiz, uno de los fundadores del MNR, profesores de la Universidad Mayor de San Andrés, de La Paz, militares y dirigentes gremiales. El ministro del Interior le había hecho saber a la embajada argentina que se los detenía "para ir neutralizando un plan de agitación", haciéndoselos salir rumbo a la Argentina con documentos de turistas. En el caso que quisieran permanecer en Buenos Aires más de un mes, debían presentarse a la Dirección de Coordinación Federal de la Policía para solicitar asilo político, gestión que no todos realizaban, quedando en situación irregular. En la Cancillería se admitía la existencia de una colonia numerosa de asilados políticos bolivianos, "sin mayores consecuencias", sobre la que se recomendaba un "control policial de sus actividades". Además "la recepción por parte de Argentina de los expulsados bolivianos es considerada por el Gobierno de ese país, principalmente por el general Ovando, como una valiosa ayuda para superar la crisis política por que atraviesa" (AHCRA, 863, Asilo/Bolivia, Buenos Aires, 29-VII-1970).

Torres sufrió su primer intento de golpe en enero de 1971, siendo señalados como dirigentes del levantamiento funcionarios de Ovando, así como Hugo Banzer, removido como director de la Escuela Militar y confinado en un remoto puesto próximo a la frontera con Chile. Las radios hicieron llamamientos a los empleados públicos, a los estudiantes y a los trabajadores para que se concentrasen en defender al gobierno, mientras se anunciaba "un plan de depuración" de opositores, anali- 
zando asimismo "la posible entrega de armas a los trabajadores para que defiendan un proceso revolucionario" (La Vanguardia, 13-I-1971). Sofocado el conato, políticos y jefes militares sublevados se refugiaron en sedes diplomática. El 14 el coronel Banzer entraba en la representación argentina. Guillermo de la Plaza gestionó la concesión de su asilo político y el salvoconducto para que el 12 de febrero partiera a Buenos Aires, en vuelo de Aerolíneas Argentinas, "a fin de rodear la partida de las garantías pertinentes (...), el asilado llegará al aeropuerto de El Alto acompañado por funcionarios de esta embajada" solicitando al ministro de Relaciones Exteriores general Emilio Molina Pizarro "la designación de un representante de esa Cancillería, así como de la custodia correspondiente" (AHCRA, 863, La Paz, 10-II-1971).

Desde Buenos Aires preocupaban no solo los asilos provenientes de la sede diplomática de La Paz, sino la llegada de ciudadanos bolivianos expatriados desde Chile que, una vez en la Argentina, intentasen "nuevas acciones". Por otro lado, negarse a los pedidos de ingreso "deformaría, según la Cancillería boliviana, la 'opinión popular' sobre prescindencia y amistad argentina". La posición jurídica oficial -trayendo a colación antecedentes históricos de 1871 ocurridos entre Argentina y Uruguay - era que nada impedía conceder asilos territoriales, la internación y consecuente vigilancia policial para que el delito de hostilidad al gobierno legal se siguiera cometiendo (AHCRA, 863, Buenos Aires, I-1971). En tanto el gobierno de La Paz acusaba a aquellos que se "habían escabullido rumbo a Chile" - entre los que había militares, políticos del MNR, funcionarios y dos exministros de Barrientos, Joaquín Villanueva y David Fernández- de preparar nuevas acciones contra las autoridades constituidas, en connivencia con grupos residentes en Brasil. La representación argentina en Santiago transmitía los reclamos de autorizaciones para los trasladados, ya que "los reclamos de los exiliados bolivianos se tornan ya angustiosos, pues algunos temen por su integridad física, aparte de tener que soportar la afligente situación económica", advirtiendo que, en caso de no ser emitida la documentación que los certificaba como asilados, estaban decididos a trasladarse por su cuenta "a Mendoza, por ómnibus, sin esperar la respuesta del pedido que han formulado". Hugo Boatti Ossorio, a cargo del Departamento de América Latina de la Cancillería, aconsejaba "conceder el asilo en virtud de que no se trata de terroristas 
(...) condicionado a la aceptación, por parte de los mismos, de su internación en la zona sur del país", pero también advirtiendo que eran "un llamado de atención para un propósito encubierto que traerían los peticionantes y que estaría en franca oposición con el espíritu que anima la concesión del asilo" (AHCRA, 863, Buenos Aires, 12-II-1971). Se exceptuaba solo un personaje, Miguel Marhemberg Kaviera, exjefe del Servicio Especial de Inteligencia boliviana. La Dirección General de Informaciones de la Cancillería opinó que "no debe accederse al pedido de asilo requerido por el causante, en razón a los antecedentes desfavorables que sobre el mismo se poseen". Su pista se pierde en lo relevado.

A principios de abril, el ministro del Interior Dr. Jorge Gallardo Lozada informó sobre un nuevo "complot subversivo" que debía estallar en esos días, dirigido por altos dirigentes del MNR, FSB (Falange Socialista Boliviana, de orientación nacionalista), grupos barrientistas y militares retirados, desplazados el 7 de octubre de 1970 y el 11 de enero, disponiéndose la detención de políticos en La Paz y en Cochabamba, muchos de los cuales fueron confinados luego en la zona tropical del Beni. En tanto, "todas las embajadas han sido objeto de vigilancia especial".

En aquel trance, Torres expulsó al embajador brasileño Hugo Bethlem (Gaspari, 2004: 347), mientras Siracusa hizo salir a su familia, creyendo que los días del gobierno estaban contados. El Departamento de Estado envió un contingente de cuatro marines entrenados para reforzar su seguridad personal (Siracusa, 1998: 59-60). De la Plaza informaba que las agrupaciones y medios "de extrema izquierda" acusaban de participar de las conspiraciones a un confuso conglomerado de "derechistas reaccionarios, falsos izquierdistas, agentes de la CIA, militares y funcionarios estadounidenses", añadiendo en su informe a la Cancillería que en sintonía actuaban "los más visibles exponentes de la izquierda marxista-leninista, la COB, la CUB (Comisión Universitaria Boliviana) y la AUB (Asociación de Universidades Bolivianas)" (AHCRA, 863, La Paz, 6-IV-71).

Las alusiones al asilo territorial que brindaba la Argentina eran directas: el matutino católico Presencia, de 3 de abril, informaba que "el movimiento subversivo que iba a estallar el 5 de abril y que se había preparado con la complicidad de algunos miembros de la Delegación 
Militar Norteamericana en La Paz, se había gestado en la ciudad de Buenos Aires, donde se habrían reunido alguno de sus dirigentes, tal el caso del general Marcos Vazquez Sepertehui". Aun cuando se consideraba que la acusación era fruto de "sectores perfectamente identificables [que] se ocupan de deformar los hechos", se socavaba la imagen de prescindencia frente a los conflictos internos bolivianos. El canciller De Pablo Pardo dio instrucciones al encargado del Departamento América Latina para que se estudiara la posibilidad de ordenar la internación de cualquier ciudadano boliviano que pudiera interferir en las relaciones con el gobierno de Torres (AHCRA, 863, Buenos Aires, 20-IV-1971).

En los meses siguientes se sucedieron las solicitudes de asilo, al compás de la tensión que se vivía en Bolivia. No se exigiría que los beneficiados tuvieran una locación determinada, sino que "fijen residencia en lugares que no justifiquen un motivo de sospecha sobre su efectivo acatamiento a las normas que rigen la materia o puedan afectar nuestras relaciones con Bolivia" (AHCRA. 863. Buenos Aires. Urgente. Secreto, 13-V-1971). Era una disyuntiva difícil de dirimir: el gobierno de Torres requería de la ayuda de Buenos Aires para alejar a los complotados; además, recibir evacuados era una manera de colaborar con el país vecino, descomprimiendo la situación; pero también, un exilio sin riguroso control policíaco podía permitir, como de hecho sucedió, la planificación de nuevos golpes institucionales. Los asilados, aunque asentados a más de mil quinientos kilómetros de la frontera argentinoboliviana y obligados a una presentación periódica en oficinas policiales, continuaron con las conjuras desde sus radicaciones entre Buenos Aires y La Plata.

\section{Argentina, Banzer y el asalto al poder}

Basado en lo publicado por el periodista argentino García Lupo ${ }^{11}$ y en sus propias investigaciones, Martín Sivak (1998) sostuvo que el temor de la poderosa colonia alemana en Bolivia, frente a la posibilidad de

11 Corresponsal del semanario uruguayo Marcha en Buenos Aires y miembro fundador de la agencia de noticias cubana Prensa Latina en 1959, Rogelio Gaarcía Lupo denunciaba en artículos de prensa publicados en la región y luego convertidos en libros (1971, 1973), las intervenciones de Onganía y Lanusse en pro de asegurar negocios y obras con la zona de Santa Cruz de la Sierra. 
que el gobierno de Torres colectivizara las granjas y expropiara empresas, la llevó a realizar colectas, comprar armamentos y dar protección a Banzer - nieto de inmigrante alemán- y otros conspiradores. También la prensa boliviana daba cuenta del acopio de dinero hecho por agrupaciones políticas opuestas. Sivak y otros autores, como Moniz Bandeira (2004: 372-3), afirman asimismo la decisiva intervención de Brasil en los hechos.

El 18 de agosto estalló finalmente el movimiento sedicioso anunciado. Mientras en Santa Cruz de la Sierra Hugo Banzer -ingresado clandestinamente al país, apresado y trasladado a La Paz- era proclamado presidente de la República por los rebeldes, el gobierno de Torres anunciaba que se estaba organizando la defensa de la capital. Ya se combatía en Oruro y Cochabamba. La rebelión del "militar calificado de fascista por sus enemigos, y partidario de una línea "dura" hacia el pueblo, bajo un régimen dictatorial avalado por la premisa del orden", contó con "la indecisión del Gobierno de Torres para hacer una entrega real de armas a sus numerosos simpatizantes (obreros y estudiantes)". Aunque la lucha callejera parecía continuar, la radio oficial transmitía al caer la noche del 21 un breve mensaje de Torres agradeciendo a quiénes "combaten por la patria inmortal" (La Vanguardia, 22-VIII-1971).

El 22 la sede diplomática argentina en La Paz informó que había acogido a la esposa de Torres y a sus tres hijos, a un cuñado suyo, al canciller Huáscar Taborga y al ministro de Defensa Emilio Molina Pizarro, junto con otros funcionarios. Los días siguientes se sucedieron los refugios de periodistas, universitarios, dirigentes políticos; algunos asilos se abandonaban para dirigirse a otras sedes diplomáticas o tras obtener los salvoconductos de salida al exterior, pero el flujo era incesante: "la guerra civil ha durado tres días; sin embargo, la represión no ha hecho más que comenzar", se leía en la prensa extranjera.

Ante la escalada de pedidos de asilo, la embajada argentina en La Paz solicitó a Buenos Aires que "se considere la posibilidad de restringir la concesión del mismo en vista de que la casi totalidad de los que lo solicitan son activos marxistas". El Departamento de América Latina de la Cancillería, bajo la jefatura de Enrique Ros, respaldó esa postura, "dada la ideología de quienes se asilan y la imposibilidad en que se encuentran los Servicios de Seguridad en controlar, debida y 
adecuadamente, la actividad que esas personas desarrollen" en la Argentina, y en atención a la posibilidad que ello plantee "un conflicto entre nuestro gobierno y las nuevas autoridades bolivianas" (AHCRA, 863, Buenos Aires, 9-IX-1971). La respuesta de la Consejería Legal fue inmediata, considerando que el asilo, tanto diplomático como territorial, tenía un carácter facultativo, que no otorgaba "un derecho de recibir asilo", siendo "indiscutible" el derecho soberano del Estado "de negar el ingreso a extranjeros sin necesidad de explicación alguna", y concluía que la embajada en La Paz podría tomar la decisión que considerará oportuna - hacer lugar a los pedidos de asilo, negarlos, o concederlos con un salvoconducto, para que los asilados se dirijan a un tercer Estado que los acepte-. Por ello, "la decisión que se adopte es eminentemente política” (AHCRA, 863, Buenos Aires, 15-IX-1971).

Las listas oficiales preparadas por los diplomáticos argentinos para identificar a los asilados en la embajada y reportarlos a Cancillería - distribuidas luego a Migraciones y policía - consignan un par de renglones con antecedentes de cada uno: "activo dirigente marxista", "militante partido socialista", "participó en grupos armados que actuaron en la universidad", "militantes izquierdistas que participaron en los combates del sábado 21.8.71", "miembro de la Asamblea Popular", "reconoció haber participado en la lucha armada"; se identifican, también, algunos ligados a la Argentina, como José Baldivia Euirdinenea "ex dirigente estudiantil de la Universidad Católica en Córdoba, año 1969", otros como los estudiantes Luis Soruco Barba, afiliado al Partido Demócrata Cristiano Revolucionario, o Juan Próspero Sánchez Rocebado, "residió en Cuba durante todo 1970" (AHCRA, 863, Asilados en la embajada de la República en Bolivia, agosto-septiembre 1971). Más allá de la cuestión ideológica, las indicaciones de agrupaciones y sindicatos de acudir al "asilo masivo en embajadas e iglesias" hacía advertir a las representaciones diplomáticas acreditadas en La Paz de la maniobra del Ministerio del Interior y de Exteriores, que procuraban empujar a los opositores a abandonar el país "a través del asilo diplomático, el que se transformaría así en un cómodo expediente administrativo, favorecido por el mismo gobierno boliviano" (AHCRA, 863, Buenos Aires, 6-X-1971).

La salida por vía de la representación argentina sumaba otra exigencia de parte del gobierno de Banzer: no querían que los deste- 
rrados se acogieran al refugio en Chile, Ecuador, Perú y Uruguay, "por considerar que se encontrarían en un medio inamistoso para el régimen" ${ }^{12}$. En Cancillería, el 8 de octubre, Enrique Ros transmitió a sus superiores sobre las gestiones que el canciller interino de Bolivia había hecho ante el nuevo embajador argentino Héctor Sánchez Iturbe, a quién le expresó "el gran interés de su gobierno en la admisión de 50 deportados para nuestro país, la que también habría sido solicitada al señor presidente de la Nación recientemente". Ros aconsejaba un criterio restrictivo respecto de las solicitudes "presentadas o a presentar", teniendo en cuenta la necesidad de contar con numerosos agentes de seguridad y automotores para trasladar al aeropuerto a más del centenar ya refugiado -incrementado con familiares junto a los cuales se habían asilado en muchos casos-, la manutención, los pasajes de avión y otros gastos que correrían por cuenta de la Argentina; eso sin contar que se estaba desvirtuando la naturaleza excepcional del asilo.

En una región de equilibrios inestables, el golpe de Banzer modificó el escenario rápidamente: se había fisurado el frente del Pacífico, al que la política exterior argentina se había acercado a pesar de la peculiaridad ideológica de Bolivia, Chile y Perú, debilitando el contrapeso que Argentina podía ejercer frente a Brasil; a la par, se favorecía y envalentonaba a los sectores conservadores y antiperonistas del Ejército para presionar a Lanusse a tomar otras posiciones en política exterior regional (AHMRECH, Fondo Argentina, Vol. 1780, $\mathrm{N}^{\circ} 1269 / 184$, 25-VIII-1071).

Lanusse se verá obligado a entrevistarse con Banzer - tras haber cursado la invitación al anterior jefe de Estado-el 19 de noviembre en la ciudad de Jujuy, capital de la provincia limítrofe con Bolivia. Un interés permanente lo justificaba: el aprovisionamiento de hidrocarburos. La revista Panorama, considerada como "portavoz de los geopolíticos argentinos", ya había atribuido a Brasil el designio de querer "retrasar un proyecto básico para el desarrollo de la siderurgia argentina: conseguir el hierro de los gigantescos yacimientos del Mutún". No siendo

12 Relata Siracusa, 1998: 67: "Most of the young extremists of the Torres regime managed to flee, many apparently going to Uruguay, Chile, Mexico and other countries hospitable to people of their political bent". 
indispensable para la economía brasileña contar con ese yacimiento, lo que parecía buscar Brasil era demorar el desarrollo argentino, contando además con otra ventaja: la explotación de su fuerza laboral, con salarios devaluados desde 1964 frente a una tasa de salarios reales en la Argentina cuatro veces superiores, defendidos por "una clase obrera organizada y combativa". Si la resistencia social en el Brasil se sometía a la mano dura de sus militares, en la "Argentina una disminución tan drástica del nivel de vida ocasionaría cordobazos en cadena" (Panorama, 17 al 23-VIII-1971).

Aunque en lo concreto se convino en incrementar las sumas que el gobierno argentino adelantaría para la realización de los estudios de las líneas férreas a las que se referían los acuerdos celebrados en La Paz el 31 de diciembre de 1970, el encuentro Lanusse-Banzer fue reflejado de manera grandilocuente en los medios de comunicación. Frente a la prensa paceña, el canciller Mario Gutiérrez — jefe de la FSB - calificó la entrevista de "histórica", principio de un diálogo directo de dos jefes de Estado, que abordarían temas como la superación de las barreras ideológicas para lograr una efectiva integración iberoamericana, que era la política propugnada por el presidente argentino (La Vanguardia, 19-XI-1971). El comandante de las Fuerzas Armadas de Bolivia, general Remberto Iriarte Paz, declaraba a la televisión argentina que, debido a que "veíamos a nuestra patria hundirse en el comunismo", Banzer había debido encabezar la toma del poder, afirmando que el nuevo presidente era "netamente nacionalista", "no de izquierda ni de derecha"13.

Respecto del pedido formulado por el presidente Banzer, "relacionado con el asilo de presos bolivianos"14, la Secretaría de Informaciones del Estado (SIDE), dependiente de la Presidencia de la Nación, se manifestó contraria. Además de repasar las razones que se venían esgrimiendo -incluso un posible ingreso masivo que afectara las fuentes de trabajo-, la principal era "impedir su vinculación y/o conexión con elementos subversivos nacionales, y con residentes de otros países limítrofes identificados ideológicamente o que se hallen enrolados en

\footnotetext{
13 Iriarte Paz venía de desempeñarse como embajador de su país en la Argentina, y se ufanaba: "tengo el insigne honor de ser amigo del general Alejandro Lanusse".

14 En un documento de la Cancillería argentina de principios de 1972, ya no se habla de 50 sino de 300 presos a deportar. Cabe preguntarse el destino de cada uno.
} 
movimientos insurreccionales de corte marxista". Finalmente el documento, dirigido al ministro de Pablo Pardo y firmado por el general Carlos Alberto Martínez, a cargo de la SIDE, afirmaba que se debía "evitar que la ARGENTINA se convierta en base de operaciones de elementos revolucionarios de extrema izquierda, cuyo accionar compromete la estabilidad de gobiernos de países amigos y aun del propio país" (AHCRA, 863, 23-XII-1971). Cuando en enero de 1972 la Nunciatura Apostólica de La Paz solicitó el concurso de la embajada argentina para conceder una visa con carácter de asilo al ciudadano boliviano Humberto Carlos Mur Gutiérrez - "de estado civil casado, de treinta y seis años de edad, de profesión auditor financiero"-, Buenos Aires la concedió, como ya había hecho antes con otros pedidos similares formulados por la representación del Vaticano, pero advirtiendo que en el futuro "no será posible acceder a nuevos pedidos". Se concluía que Bolivia "se encuentra en plena tranquilidad y no existe persecución de carácter político que justifique el asilo" (AHCRA, 863, Buenos Aires, 18-I-1972).

\section{Consideraciones finales}

Comenzando 1972 las autoridades de la Revolución Argentina se mostraban conformes con el rumbo que habían tomado las relaciones con Bolivia, en los dos aspectos que más habían preocupado los últimos años: lo geopolítico y el control de los asilos oficiales.

Desde su alto cargo en Cancillería, Guillermo de la Plaza se entrevistó con altos mandos militares para tratar el problema del "excesivo otorgamiento de asilo diplomático" en Bolivia y "su evidente orientación marxista". Explicó que el criterio a aplicar sería en adelante el de la restricción, "en atención a la ideología de quienes se asilaban y a la imposibilidad por parte de los servicios de seguridad de controlar, debida y adecuadamente, la actividad que estas personas puedan desarrollar en nuestro país", suscitando algo que se quería evitar: "un conflicto entre nuestro país y las nuevas autoridades bolivianas" (AHCRA, 863. Buenos Aires, 8-XII-1971). Habían colisionado, pues, intereses y principios de política exterior: los motivos de seguridad nacional para limitar los asilos y la tradición jurídica para mantenerlos, en mínimos y dentro del "marco estricto de las normas".

En coincidencia, la cambiante situación del Cono Sur era monitoreada por pedido de la SIDE, solicitándose a la Cancillería informes 
periódicos "con el objeto de actualizar y completar la Apreciación de Inteligencia Estratégica Nacional". Para ello se formó un comité de trabajo del que participaron el subsecretario de Relaciones Exteriores y Culto, José María Ruda, De la Plaza, el diplomático de carrera Ernesto Malpede, y el jefe del Departamento Exterior de la SIDE, capitán de fragata (RE) Carlos Viganó (AHCRA, 863, Buenos Aires, 23-XII-1971). El 2 de febrero se envió al presidente Lanusse una detallada exposición en la que, además de analizar la realidad de cada país en particular, enmarcada en el contexto regional y mundial debido a "la variación de las corrientes ideológicas cuyos centros son Pekín, Moscú y La Habana", se proponían "las soluciones y modos de acción". El anexo 1 estaba dedicado a Bolivia, considerándose zanjado el "ingrediente negativo" motivado por el rechazo a recibir los presos expulsados, ofreciéndole en cambio aceptar asilos mientras se encuadrasen "en el marco de su verdadero contenido, a fin de no desnaturalizar el ejercicio de este derecho" - eufemismo jurídico-diplomático que se podría traducir en excusa para no concederlo tanto a los sindicados como a militantes de izquierda. En referencia a los suministros de minerales, petróleo y gas que Argentina precisaba y "la gran promoción y ofensiva política que viene desarrollando Brasil", el gobierno de Banzer seguía dispuesto a mantener y cuidar sus buenas relaciones con Buenos Aires, "por su caótica situación económica y su falta de abastecimiento en el orden alimentario". El nexo binacional se hallaba bajo la positiva influencia de la visita del canciller de Torres en julio de 1971 y, "fundamentalmente", de la entrevista de los presidentes en Jujuy, urgiéndose a avanzar con todo lo planeado, asignando las partidas presupuestas necesarias, a efectos de "contrarrestar la fuerte ofensiva brasileña (...) se sabe que Brasil, en cuanto a las obras que ha realizado, no han conformado a las autoridades bolivianas" (AHCRA, Fondo E, AH/0050, 10-II-1972).

Aquel elenco de gestores de la política exterior argentina se manifestaba persuadido de haber dado eficaces pasos para controlar tanto la circulación de marxistas hacía el país como la expansión y la atracción del modelo brasileño, sin desconocer el posible arraigo de ambas concepciones políticas e ideológicas en sectores nacionales, cuya real entidad era una incógnita, aún. 


\section{Referencias bibliográficas}

Fuentes primarias

a. Publicaciones periódicas

Clarín, Buenos Aires, 1970-1971.

Confirmado, Buenos Aires, 1967-1971.

El País, Madrid, 11-VI-1976.

La Vanguardia, Barcelona, 1966-1972.

Panorama, Buenos Aires, 1966-1972.

Periscopio, Buenos Aires, 1970-1971.

Primera Plana, Buenos Aires, 1966-1972.

Siete Días, Buenos Aires, No 180, 9 al 25-X-1970.

Triunfo, Madrid, 12-XII-1970.

\section{b. Fuentes documentales}

Asilo/Bolivia. Expediente 863 y Fondo E, Chile-Argentina. Archivo Histórico de la Cancillería Argentina, 1969-1972, Buenos Aires.

Fondo Argentina. Archivo Histórico del Ministerio de Relaciones Exteriores de Chile. 1970-1972, Santiago.

Argentina-Relaciones con Bolivia. Archivo del Ministerio de Asuntos Exteriores de España. 1969-1971, Madrid.

\section{c. Publicaciones oficiales}

Argentina. Ley 21.202, 13-11-1975.

Bolivia. (1966). Así fueron las elecciones de 1966. La Paz: Dirección de Prensa e Informaciones-Presidencia de la República.

Círculo Diplomático Argentino (1969). Rol protagónico de la República Argentina en el ámbito latinoamericano. Conferencia pronunciada por el embajador Guillermo de la Plaza, el 18 de octubre de 1968, en el Instituto de Enseñanza Superior del Ejército y Centro de Altos Estudios, en oportunidad del IV Curso Interfuerzas, Buenos Aires.

Fuentes secundarias

a. Artículos y capítulos de libros

Araujo, A. L. y C. G. P. Teixeira (2015). "A posição do Brasil no sistema diplomático da Bacia do Prata entre 1969 e 1974", en Boletín Meridiano 47, Vol. 16, N 148, mar.-abr., pp. 10-17. 
Carrizo, S. C. y D. Ramousse (2010). "Dinámicas energéticas e integración regional en el noroeste argentino y el sur boliviano", en Revista de Geografía Norte Grande, $\mathrm{N}^{\circ} 45$, pp. 51-62.

Figallo, B. y M. J. Henríquez, (2009). "El plan iberoamericano del franquismo. El Cono Sur y la doctrina López Bravo. 1969-1973”, en Estudios Latinoamericanos, Año 1, № 2, pp. 22-48.

Figallo, B. (2013). "Las migraciones políticas en la Argentina del siglo XX. Núcleos de confrontación y exclusiones", en Figallo, B. y M. R. Cozzani (editoras). Los de adentro y los de afuera. Exclusiones e integraciones de proyectos de nación en la Argentina y América Latina. Rosario: IDEHESI-IH, pp. 45-100.

Joseph, G. M. (2019). "Border Crossings and the Remaking of Latin American Cold War Studies", en Cold War History, Volume 19, Issue 1, pp. 141-170.

Leal Buitrago, F. (2003). "La Doctrina de Seguridad Nacional: materialización de la Guerra Fría en América del Sur", en Revista de Estudios Sociales, $\mathrm{N}^{\circ} 15$, pp. 74-87.

Marchesi, A. (2018-2019). 'El llanto en tu nombre es una gran traición'. Lecturas políticas y emocionales de la muerte de Ernesto Guevara en el Cono Sur (1967-1968)", en Políticas de la Memoria. Anuario de Investigación e Información del CeDInCI (Centro de Documentación e Investigación de la Cultura de Izquierdas), $\mathrm{N}^{\circ} 18$, pp. 123-135.

Marini, R. C. y O. Pellicer de Brody (Jul.-Sep.,1967). "Militarismo y desnuclearización en América Latina. El Caso de Brasil", en Foro Internacional, Vol. 8, $\mathrm{N}^{\circ} 1$ (29), pp. 1-24.

Miguez, M. C. (2013). "Anticomunistas, antiestatistas, antiperonistas? La "nacionalización" de la Doctrina de Seguridad Nacional en la Argentina y la legitimación del golpe de estado de 1966", en Revista de la Sociedad Argentina de Análisis Político, Vol. 7, N 1, pp. 65-95.

Rodríguez Ostria, G. (2005). “Teoponte: la otra guerrilla guevarista en Bolivia", en Lucha Armada en la Argentina, Año 1, ํ 2, pp. 88-97.

Rodríguez Ostria, G. (2018/2019). "El legado del Che. Del Ejército de Liberación Nacional al Partido Revolucionario de los Trabajadores en Bolivia (1967-1977)", en Políticas de la Memoria. Anuario de Investigación e Información del CeDInCI (Centro de Documentación e Investigación de la Cultura de Izquierdas), $\mathrm{N}^{\circ} 18$, pp. 80-108. 
Vizentini, P. F. (1998-1999). “Política Externa e desenvolvimento no regime militar", en Principios, 51, nov/dez/jan, pp. 56-65.

\section{b. Libros}

Gandarillas, M., M. Tahbub y G. Rodríguez (2008). Nacionalización de los hidrocarburos en Bolivia: la lucha de un pueblo por sus recursos naturales. Barcelona: Icaria.

García Lupo, R. (1971). Mercenarios \& monopolios en la Argentina de Onganía a Lanusse. 1966-1971. Buenos Aires: Achával Solo.

García Lupo, R. (1973). La Argentina en la selva mundial. Buenos Aires: Corregidor.

Gaspari, Elio (2004). A ditadura derrotada. São Paulo: Companhia das Letras.

Lanusse, A. A. (1977). Mi testimonio. Buenos Aires: Lasserre.

Moniz Bandeira, L. A. (2004). Argentina, Brasil y Estados Unidos de la Triple Alianza al Mercosur. Conflicto e integración en América del Sur. Buenos Aires: Norma.

Rodas Morales, H. (2008). Marcelo Quiroga Santa Cruz. El socialismo vivido. Tomo II (1969-1977). La Paz: Plural.

Rodas Morales, H. (2010). Marcelo Quiroga Santa Cruz. El socialismo vivido. Tomo I (1931-1968). La Paz: Plural Editores.

Sivak, M. (1998). El asesinato de Juan José Torres. Banzer y el Mercosur de la Muerte. Buenos Aires: Ediciones del Pensamiento Nacional.

Suárez, H. J. (2003). ¿Ser cristiano es ser de izquierda? La experiencia político-religiosa del cristianismo de la liberación en Bolivia en los años 60. La Paz: Muela del Diablo Editores.

\section{c. Otros}

Documental Algo Quema (2018), Bolivia. Dirección: Mauricio Ovando. Guerra Vilaboy, S. (2021). “Gobierno nacionalista de J. J. Torres en Bolivia", en Informe fracto. Disponible en https://informefracto. com/la-nacion-y-el-mundo/madre-america/gobierno-nacionalista-de-j-j-torres-en-bolivia/, revisado el 3-IV-2021.

Padilla Rodríguez, L. (2007). Estudio y análisis de la política energética de Bolivia. Tesis para obtener la Maestría en Estudios Internacionales, Instituto Tecnológico y de Estudios Superiores de Monterrey. México. Disponible en https://repositorio. 
tec.mx/bitstream/handle/11285/629205/33068001074084. pdf? sequence=1\&isAllowed=y, revisado: 30-VI-2021.

Salazar Calvo, M. (2020). “Elmo Catalán, el periodista chileno que siguió los pasos del Che Guevara". Disponible en https:// interferencia.cl/articulos/elmo-catalan-el-periodista-chileno-que-siguio-los-pasos-del-che-guevara, revisado el 20VII-2021.

Siracusa, E. V., ambassador (1998). The Association for Diplomatic Studies and Training Foreign Affairs Oral History Project. Interviewed by: Hank Zivetz Initial interview date: June 1989.

Sitio web de la Gaceta Oficial de Bolivia. Disponible en https://www. derechoteca.com/gacetabolivia, decreto N.o 07815, del 22IX-1966, revisado el 1-IV-2021.

Sitio web de Telam. Argentina. Disponible en https://www.telam.com. ar/notas/201308/28399-la-dictadura-argentina-aporto-napalm-a-bolivia-para-combatir-al-che.php, revisado el 1-III2021.

Sitio web de Tiempo Argentino, 30-IV-2018. Argentina. Disponible en https://www.tiempoar.com.ar/nota/un-lamento-boliviano, revisado el 2-IV-2021. 